\title{
RESEARCHPAPER
}

\section{Efficacy of polyethylene glycol (PEG) induced drought on germination indices and photosynthetic pigments of sweet corn var. NSC-901B}

\author{
SUHANA RAO, RAMESHWAR GROACH, SOMBIR SINGH AND NARENDER SINGH
}

Department of Botany, Plant Physiology and Biochemistry Laboratory, Kurukshetra University, KURUKSHETRA (HARYANA) INDIA

Email : rameshwar.groach@kuk.ac.in

Article Info : Received : 10.07.2017; Revised : 15.08.2017; Accepted : 13.09.2017

Germination of seed is considered as the first and most fundamental stage of a plant life cycle so that, the achievement in growth and yield production also depends on this stage. Drought stress is one of the most important environmental factors that limit the growth, development and production of plants. The influence of drought stress $(0,-.6,-1.2$ and -1.8 bar) by polyethylene glycol (PEG) 6000 on seed germination indices and photosynthetic pigments in sweet corn was examined under laboratory conditions with triplicates. Results indicated that drought stress significantly reduced germination per cent (76\%), radicle length (71\%), plumule length (65\%), radicle fresh weight (76\%), plumule fresh weight (68\%), radicle dry weight (78\%), plumule dry weight (56\%), chlorophyll a (67\%), chlorophyll b (75\%), total chlorophyll (69\%) and carotenoids (72\%). Overall, drought stress had a negative effect on all the parameters.

Key words : Drought stress, PEG, Photosynthetic pigments, Seed germination, Seedling growth

How to cite this paper : Rao, Suhana, Groach, Rameshwar, Singh, Sombir and Singh, Narender (2017). Efficacy of polyethylene glycol (PEG) induced drought on germination indices and photosynthetic pigments of sweet corn var. NSC-901B. Asian J. Bio. Sci., 12 (2) : 185-188.DOI : 10.15740/HAS/AJBS/12.2/185-188. 